\title{
К МЕТОДОЛОГИИ ИССЛЕДОВАНИЯ СОЦИАЛЬНЫХ СЕТЕЙ
}

\author{
C. B. Кураева \\ Московский гуманитарный университет
}

Аннотация: В статье описаны характеристики социальных сетей, которыми пользуются интернет-пользователи России. Приведены некоторые результаты дискурса о возможностях и перспективах исследования социальных сетей. Определены методологические подходы для исследования самопрезентации и идентификации в социальных сетях.

Ключевые слова: социальные сети; феноменологическая теория; социальное конструирование реальности; драматургический подход И. Гофмана; коммуникативные подходы; комплексный подход

\section{ON THE METHODOLOGY OF SOCIAL NETWORKS RESEARCH}

\author{
S. A. Kurayeva \\ Moscow University for the Humanities
}

Abstract: The article examines the characteristics of social networks used by Russian Internet users. It presents the results of a discourse on the possibilities and prospects of the study of social networks. Methodological approaches for researching self-presentation and identification in social networks are defined.

Keywords: social networks; phenomenological theory; social construction of reality; I. Hoffmann's dramaturgic approach; communicative approaches; integrated approach

Масштабное и стремительное развитие Интернета влечет за собой изменение пространственно-временных характеристик и появление новых форм и способов коммуникации, изменение традиционных и становление новых форм социальных институтов, появление новых социальных практик и других новаций, происходящих на разных уровнях. В настоящее время виртуальная реальность буквально вплетена в социальную реальность, стала ее частью. Согласно известной теореме У. Томаса, если нечто воспринимается индивидом как реальность, то и последствия реальны (см.: Хаустов, 2012). В этой связи наибольший исследовательский интерес представляет феномен социальных сетей. 
В России, по нашим оценкам, 39\% от общего количества пользователей Интернет (это 73\% населения РФ) активно пользуются социальными сетями. В среднем пользователи проводят в социальных сетях 2 часа 19 минут, что составляет $1 / 4$ рабочего времени при 8 часовом рабочем дне и $1 / 3$ от среднего количества времени, проводимого студентом в университете (Digital in 2017 global overview: Электр. ресурс).

Социальные сети активно исследуются в психологии (Королева, Томилова, 2017: Электр. ресурс), социологии (Щекотуров, 2012), антропологии (Карасева, 2017: Электр. ресурс), политологии (Дряева, 2017: Электр. ресурс).

Данные социальных сетей отражают разные аспекты жизни человека, они генерируются пользователями в непрерывном потоке: аватары, текстовые и мультимедийные публикации, комментарии, эмоциональные отклики (от отметки «нравится» до сложных «эмодзи» выражающих оттенки эмоционального состояния и отношения), перепубликации и другое. На сегодняшний день специалисты накапливают эти данные и разрабатывают подходы к их анализу. По итогам дискуссии: «Соцсети для исследователей: люди, боты или поток контента?» было обозначено наличие ограничений при анализе данных социальных сетей, приведем некоторые из них: не все аспекты жизни человека можно анализировать, используя социальные сети; данные анализируются «как они есть», сложно запланировать результат; из большого объема информации необходимо выделять «полезные» данные; анализировать можно только открытый (доступный для всеобщего ознакомления) контент. Аналитические технологии обработки данных, действующие в интересах, прежде всего бизнеса, ориентированы на количественные показатели, в то время как для качественного анализа требуется «исследовательское вмешательство». По мнению экспертов, дискутировавших в Фонде общественного мнения 26 июня 2017 г., именно качественные социологические исследования способны определить новые векторы анализа (Социальные сети для исследователей ..., 2017: Электр. ресурс).

Социальные сети (сообщества) как объект социологического исследования - явление сложное, многоуровневое. Этот факт определяет множество его предметных свойств: цели и мотивы присутствия, самопрезентация индивида, способы и частота коммуникации, выбор способов коммуникаций в зависимости от общественного мнения в сетевом сообществе (мнений «друзей», мнений «друзей друзей»), самоидентификация пользователей, характер устанавливаемых внутригрупповых связей, внутригрупповые нормы и правила, типы сетевой структуры и многое другое.

Социальные сети обретают свою специфику посредством выработки своей статусной системы, формирования своей культуры, раскрываемой 
через язык, нормы и традиции (Силаева, 2008). Варианты классификации сетей определяются конкретным предметом изучения: по объему пользователей; открытые и закрытые сети; по характеру публикуемого контента (медиа файлы, тексты); по объему сообщения (140 печатных знака в Twitter или объемный пост в Facebook); по времени доступа получателей к сообщению (архивное хранение публикаций для доступа в Facebook, ВКонтакте или удаление сообщения после просмотра через 10 секунд в Snapchat); контактные и контекстные сети; возможность синхронизации публикуемых данных с другими сетями (одновременная публикация в Facebook и Instagram).

Особое внимание мы бы хотели уделить контактным и контекстным социальным сетям, что обусловлено характером взаимодействия участников, в процессе которого возможно наиболее полно раскрыть понятия «самопрезентация» и «идентичность», определив соответствующие методологические принципы.

Контактные социальные сети устанавливают связи между участниками характеризующиеся не только обменом информацией различного генеза доступной для некоторой группы (медиа файлы, комментарии, перепубликации), но и возможностью установления более тесного межличностного контакта между двумя участниками группы. К данному типу сетей относятся: ВКонтакте, Facebook, Одноклассники, My space и другие.

Контекстные социальные сети, такие как Twitter, Instagram, Snapchat являются информационными каналами, в которых участники получают и транслируют информацию, выражают свое мнение, обмениваются репликами, но при этом не имеют возможности установления «закрытых» для других личных контактов.

Характер использования социальных сетей (частота обращения, продолжительность присутствия, наполняемость аккаунта (личной страницы), публичность (разрешенный доступ к личным данным) и далее) определяет пользователей как: как потребители новостей (используют социальные сети для получения новостного контента); активные пользователи (поддерживают общение с близкими друзьям и знакомыми посредством сообщества, получают новостную информацию); генераторы контента (создают новости и события, делают акцент на репрезентации социальной сети), имеющие аккаунт в сети и поддерживающие общение с определенным кругом людей (Докука, 2014).

Среди методологических подходов социологии выделим наиболее эвристичные для разных аспектов анализа социальных сетей.

Масштаб распространения, темпы роста числа участников, время, проводимое в социальных сетях, частота использования социальных сетей позволяет нам говорить о том, что социальные сетей стали явлением 
повседневной жизни. Исследование повседневности возможно в рамках феноменологического подхода, разработанного А. Щюцем. Основная идея его теории - о множественности реальностей мира: реальность науки, религии искусства, снов и далее, но главной среди них является повседневная жизнь. Обыденное, повседневное знание и его распределение в конкретной социальной группе в определенной исторической и культурной обстановке стало основным предметом исследования. Каждая социальная группа определяет свою социальную реальность на основе типизации явлений: члены общества (группы) вступают в контакт, будучи уверенными, что другие члены группы видят мир таким же образом и это становится отправной точкой для взаимодействия. Постепенно индивид создает «знание здравого смысла», которое разделяют и другие члены общества, что позволяет им жить сообща. Формируемый социокультурный мир узкой социальной группы воспринимается как мир объективный и является миром значений. Посредством декодирования значений человек может объяснить действия другого. Узкие «домашние» группы могут различаться между собой и тогда формируются понятия «Мы-группа» и «Они-группа». При переходе индивида из одной социальной группы в другую ему неизбежно приходится сталкиваться с тем, что члены новой группы руководствуются своими (иными) знаниями, имеют свою (иную) специфическую шкалу измерения значений и социальных объектов (Щюц, 2003).

Данный подход позволяет исследовать идентичность в социальных сетях и сообществах (группах) внутри них. Каждый пользователь социальной сети может быть участником множества групп $(1,10,150$ групп и более). Это будет индикатором интереса пользователя, а при детальном изучении вовлеченности (частоты посещения, активности публикаций в зависимости от формы общения в группе: поставить «лайк», оставить комментарий, сделать «репост») можно делать выводы о доминирующем интересе. Содержание и характер публикаций будет зависеть от получателей: свои/чужие. Как вариант разделения на свои/чужие группы знакомых в реальности (офлайн) людей (одноклассники, родственники, коллеги и далее) и исключительно виртуальные (онлайн) контакты которые не поддерживаются в реальности.

Социальное конструирование реальности Т. Лукмана и П. Бергера, как продолжение феноменологической теории, позволяет описать действия субъектов в рамках определенных моделей, показать их способность конструировать саму социальную реальность и оказывать обратное влияние на общество и его институциональные структуры. Понятия процесса социализации, описанные авторами, используются исследователями для анализа влияния информации на жизненные стратегии. Плюра- 
лизм жизненных миров и стратегий, отражаемый через социальные сети, оказывает влияние на вторичную социализацию человека, в процессе которой продолжается процесс идентификации, происходит перестройка менталитета и поведения. В тоже время, человек находится в процессе конструирования реальности вокруг себя, выражающееся через действия и самовыражение, с приданием значимости для себя и других (Бергер, Лукман, 1995: 63).

Эти два процесса интернализации (усвоения) и экстернализации (выражения) возможно проанализировать, используя социальные сети. При этом, мы сможем оценить не только состояние на момент исследования, но и обратиться к ретроспективным данным содержащимся в социальных сетях. Для применения данного подхода требуется доступ к сохраненным данным на странице пользователя. К примеру: соотнесение публикуемой на собственной странице информации (экстернализация) с содержанием подписок на различные группы и личности (интернализация) и рассмотрение этого в ретроспективе. Особый исследовательский интерес представляет соотнесение социальной (офлайн) реальности, наполненной событиями, и отображение отношения к ним в социальных сетях, где люди могут быть более свободны в выражениях своего отношения. Это свобода самовыражения достигается за счет возможности выбора тех, кому будет доступна данная информация (например, в Facebook выбор конфиденциальности публикации представлен вариантами: Bce нa Facebook и вне его; Только я; Конкретные друзья; Друзья кроме ...; Друзья на Facebook).

Возникающий процесс коммуникации между личностью и группой возможно анализировать в рамках подходов, предложенных У. Липманном и Э. Бернейсом (Липманн, 2004; Бернейс, 2012). Для характеристики восприятия окружающей действительности, Липманн использовал термин «псевдосреда» и «стереотип». «Псевдосреда» является фикцией окружающего мира, которая позволяет упрощать восприятие его сложной, разноликой и многоаспектной природы. «Это подобно пьесе, подсказанной актерам их собственным жизненным опытом, в которой сюжет разыгрывается в реальной жизни актеров, а не на сцене. Эта двойная драма внутреннего мотива и внешнего» (Липманн, 2004: 4). «Псевдосреда» насыщена стереотипами, которые человек усваивает и накапливает в процессе жизни, через них он создает эту среду. Основные функции стереотипа: упорядочивание противоречивой картины мира (люди вещи и события занимаю свои места, им присваиваются свои значения); защита самоуважения человека («проецируют во внешний мир осознание наших ценностей; защищают наше положение в обществе и наши права») и защита от восприятия отвлекающих образов, которые могут нарушить выбранный путь. Стереотипическое мышление способствует выборочному 
восприятию фактов и придание им специфического значения. Контент страницы пользователя в некоторой степени отражает набор стереотипов как тех, которые человек придерживается в реальной жизни, так и заимствованных в виртуальном пространстве. Анализируя, в ретроспективе, содержание личной страницы возможно отследить изменение стереотипов во времени.

Важной характеристикой коммуникации, которая осуществляется в современном обществе, является эффект (влияние), который создает коммуникация. Информация становится инструментом воздействия. Разработанная Э. Бернейсом прикладная дисциплина «Паблик рилейшнз» может решать многие задачи, связанные с управлением общественным мнением. Такие понятия как информационные потоки, созданные с определенной целью; лидеры мнений; группа воздействия; создание нужного впечатления; создание обстоятельств, которые смогут косвенно воздействовать на группу, мы можем проследить при рассмотрении распространения информации в социальной сети. «Лидеры мнений» - блогеры, лица, регулярно ведущие личную страницы с добавлением текста, изображения и мультимедиа (Селиверстова, 2015: Электр. ресурс).

Повседневные коммуникации и самопрезентации в социальных сетях могут быть проанализированы через драматургический подход И. Гофмана. Социальную сеть можно рассматривать как «театр», участники - «актеры», интеракции между ними и самопрезентации участников способ преодоления внутриличностных противоречий и нереализованных потребностей возникающих вследствие несоответствия инстинктивных потребностей правилам, принятым в обществе (Гофман, 2000).

Контент социальных сетей в полной мере предоставляет возможности для анализа как используемых «масок» (сознательно созданный контент), так и выявления истинных интересов и потребностей (подписки на интересующие ресурсы, оставляемые комментарии, отметки другими пользователями). Активность человека в социальной сети можно оценивать, как «исполнение» перед другими пользователями (зрителями). В процессе данной коммуникации происходит создание впечатлений, которое можно разделить на два вида знакового обмена: произвольный и непроизвольный. К произвольному можно отнести: публикуемые на личной странице фотографии, тексты и иные виды информации, созданные человеком в рамках своей личной страницы, одной из целей которой будет представление себя. К непроизвольным: подписки на различные страницы, оставляемые пользователем комментарии (вне страницы самого пользователя), характер списка контактов, и иные виды активности за рамками личной страницы. Асимметрия коммуникации заключается в том, что индивид осознает лишь один из каналов коммуникации, в то 
время как аудитория воспринимает информацию по двум каналам. Таким образом, транслируемая информация может проверяться аудиторией на соответствие истине с оценкой прежде всего невербального канала (в случае социальных сообществ, пользовательской активности за рамками собственной страницы), т. е. тому информационному потоку, который и выдает актора.

Более детальное рассмотрение понятий драматургического подхода таких как: исполнение, передний и личный план; театральное воплощение, идеализация; поддержание экспрессивного контроля; мистификация; действительность и уловки; команды; зоны и зональное поведение, могут быть применены к анализу самопрезентации в социальных сетях с определенными ограничениями.

Приведенные методологические подходы содержат отсылки к значимости контекста изучаемого объекта, который определяет характер самопрезентации по Гофману; реакцию на события, с учетом влияния «домашней группы» по Щюцу; генерируемая информация с учетом ранее усвоенной по Лукману и Бергеру; управление информацией в контексте достижения личных целей у Бернейса; оценка влияния «псевдосреды» и стереопитов на представление себя и отождествления с другими у Липмана; исследование приведенных аспектов социальных сетей, а особенно самопрезетации и идентичности, может быть наиболее полным, объективным и достоверным если его производить в контексте реальной жизни объекта и предмета исследования (Miller, 2013: Электр. pесурс); исследование контента личной страницы пользователя и встреча в реальной жизни, соотнесение данных публикуемых человеком и проведение интервью по темам значений, смыслов действий пользователя в социальной сети; использование и комбинация смешанных методов зависит от исследователя, его целей и возможностей.

Неизменным остается изучение онлайн и офлайн реальностей в совокупности, а не противопоставляя одно другому.

Таким образом, социальные сети, как объект социологического исследования, предоставляет большое количество материала для анализа в различных его аспектах, дает возможность апробации смешанных методов исследования и формировании новых подходов, что в свою очередь обогащает социологический инструментарий.

\section{СПИСОК ЛИТЕРАТУРЫ}

Бергер, П., Лукман, Т. (1995) Социальное конструирование реальности. Трактат по социологии знания. М. : Медиум. 323 с.

Бернейс, Э. (2012) Манипуляция общественным мнением: как и почему // Политические исследования. № 4. С. 149-159. 
Гофман, И. (2000) Представление себя другим в повседневной жизни / пер. с англ. и вступ. статья А. Д. Ковалева. М.: Канон-Пресс-Ц, Кучково поле. 304 с.

Докука, С. В. (2014) Практика использования онлайновых сетей // Социологические исследования. № 1. С. 137-145.

Дряева, Э. (2017) Самопрезентация российских политиков в социальных сетях: современное состояние и перспективы [Электронный ресурс] // Saundcloud. URL: https://soundcloud.com/clubforinternetandsociety/ pecha-kucha-dryaeva?in=clubforinternetandsociety/sets/lqnxpjvaolgf. (дата обращения: 04.09. 2017).

Карасева, А. (2017) Транс локальный Магадан: «виртуальное соседство» в BK-паблике «MGDN Магадан» [Электронный ресурс] // Вторая международная конференция «Интернет по ту сторону цифр». URL: URL:https://drive.google.com/file/d/0BwSZtTOaUSGJZDNxS1NXaDhzaTQ/ view (дата обращения: 5.09.2017).

Королева Д., Томилова Е. (2017) «Портрет» современного подростка через его самопрезентацию в социальной сети [Электронный ресурс] // Вторая международная конференция «Интернет по ту сторону цифр». URL: https://drive.google.com/file/d/0BwSZtTOaUSGJSTd0N1ZxaTVaOU0/ view (дата обращения: 5.09.2017).

Липман, У. (2004) Общественное мнение / пер. с англ. Т. В. Барчуновой. М. : Институт Фонда «Общественное мнение». 384 с.

Селиверстова, Н. А. (2015) Блогер [Электронный ресурс] // Социология молодежи. Электронная энциклопедия / под ред. проф. Вал. А. Лукова. URL: http://www.soc-mol.ru/encyclopaedia/youth/11-bloger.html (дата обращения: 15.09.2017).

Силаева, В. Л. (2008) Интернет как социальный феномен // Социологические исследования. № 11. С. 101-107.

Хаустов, Д. С. (2012) Теорема Томаса и особенности конструирования социальной реальности через массовые коммуникации // Социологические исследования. № 7. С. 29-36.

Щекотуров, А. В. (2012) Гендерные самопрезентации подростков на страницах социальной сети «ВКОНТАКТЕ» // Мониторинг общественного мнения. № 4. С. 80-88.

Шюц, А. (2003) Смысловая структура повседневного мира: очерки по феноменологической социологии / сост. А. Я. Алхасов; пер. с англ. А. Я. Алхасова, Н. Я. Мазлумяновой. М. : Институт Фонда «Общественное мнение». 336 с.

Социальные сети для исследователей: люди, боты или поток контента? (2017) [Электронный ресурс] // Yutube.com. 26 июня. URL: https://www. youtube.com/watch?v=gZQ2seTrtzs \&list=PLEivdR9jouZWf6hdRt8bU7TpJ3uc 
Cff1F\&index=2 (дата обращения: 15.09.2017).

Miller, D. (2013) Future Identities Changing identities in the UK: the next 10 years [Электронный ресурс] // Gov.uk. URL: https://www.gov.uk/ government/uploads/system/uploads/attachment_data/file/273968/13524-future-identities-changing-identities-summary.pdf (дата обращения: 4.10.2017).

Digital in 2017 global overview 2017 [Электронный ресурс]//Wearesocial. com. URL: https://wearesocial.com/special-reports/digital-in-2017-globaloverview (дата обращения: 3.10.2017).

Дата поступления: 05.10.2017 2.

Кураева Светлана Александровна - студентка магистратуры факультета психологии, педагогики и социологии Московского гуманитарного университета. Адрес: 111395, Россия, г. Москва, ул. Юности, д. 5. Тел. +7 (499) 374-75-95. Эл. адрес: s-kuraeva@yandex.ru. Научный руководитель - д-р социол. н., проф. Н. А. Селиверстова.

Kurayeva Svetlana Aleksandrovna, Graduate Student, Faculty of Psychology, Pedagogy and Sociology, Moscow University for the Humanities. Postal address: 5, Yunosti St., Moscow, Russian Federation 111395. Tel.: +7(499) 374-75-95. E-mail: s-kuraeva@yandex.ru. Scientific Adviser N. A. Seliverstova, Doctor of Sociology, Professor.

\section{Для цзитирования:}

Кураева С. А. К методологии исследования социальных сетей [Электронный ресурс] // Научные труды Московского гуманитарного университета. 2017. № 5. URL: http://journals.mosgu.ru/trudy/article/view/567 DOI: 10.17805/trudy.2017.5.5 (дата обращения: дд.мм.гг.). 